\title{
Comparison of Taura syndrome virus (TSV) detection methods during chronic-phase infection in Penaeus vannamei
}

\author{
B. T. Poulos, B. W. Noble, D. V. Lightner* \\ The University of Arizona, Aquaculture Pathology Laboratory, Dept. Veterinary Science and Microbiology, \\ 1117 E. Lowell St., Tucson, Arizona 85719, USA
}

\begin{abstract}
Methods to detect Taura syndrome virus (TSV) were assessed for their ability to detect the virus during chronic phase infection in the Pacific white shrimp Penaeus vannamei. In situ hybridization (ISH), immunohistochemistry (IHC) using monoclonal antibody 1A1, conventional RTPCR and real-time quantitative (q)RT-PCR were compared using shrimp sampled over 60 wk following experimental TSV infection. Between Weeks 7 and 60, hematoxylin-eosin histology confirmed the presence of lymphoid organ spheroids (LOS) and an absence of lesions in the cuticular epithelium. ISH detected TSV in LOS over the duration of the study. IHC was generally less sensitive than ISH, and after Week 24, was often unable to confirm TSV infection. Detection of TSV by RT-PCR was highly dependent on sample source after Week 43, where viral RNA was detected in 12 of 14 hemolymph samples but only 5 of 16 pleopod samples. qRT-PCR detected TSV over the 60 wk in both hemolymph and pleopods, although RNA copy numbers in pleopods were consistently lower throughout the study. This study demonstrates that ISH and qRT-PCR are the most reliable methods for detecting TSV during late chronic phase infection. RT-PCR was also reliable if hemolymph was used as the sample source.
\end{abstract}

KEY WORDS: Taura syndrome $\cdot \mathrm{TSV} \cdot \mathrm{RT}-\mathrm{PCR} \cdot \mathrm{qRT}-\mathrm{PCR} \cdot$ In situ hybridization · Immunohistochemistry

\section{INTRODUCTION}

Taura syndrome (TS) is a viral disease of the penaeid shrimp Penaeus vannamei and P. stylirostris, characterized by a highly lethal acute phase followed by a life-long chronic phase in survivors (Lightner et al. 1995, Hasson et al. 1995,1999a,b, Erickson et al. 2002, 2005). First seen in shrimp farms located along the Taura River in Ecuador in 1992, TS spread rapidly to other countries in Central and South America and to Mexico and the United States (Jimenez 1992, Brock et al. 1995, Brock 1997). The introduction of $P$. vannamei culture in Taiwan, China, Thailand and Indonesia also resulted in the spread of TS virus (TSV) to these regions within a relatively short period of time (Tu et al. 1999, Yu \& Song 2000, Nielsen et al. 2005, Tang \& Lightner 2005). Several genotypes or strains are now known to exist and the virus remains an important infectious disease in countries where $P$. vannamei is farmed (Erickson et al. 2002, 2005, Lien et al. 2002, Robles-Sikisaka et al. 2002, Rosenberry 2002, Tang \& Lightner 2005).

Microscopic examination, molecular probes and serological methods have been developed to detect TSV in clinical samples. Initially, TSV infection was diagnosed using a combination of gross disease signs and histopathology (Lightner et al. 1995). Acute-phase TSV lesions found in the cuticular epithelium appear as multifocal areas of necrosis marked by the presence of numerous eosinophillic to basophilic cytoplasmic inclusion bodies that give the lesions a 'buckshot' appearance. Hasson et al. (1999a) demonstrated that the TSV disease cycle in Penaeus vannamei has a short $(\sim 7 \mathrm{~d})$ acute phase followed by a transition phase 
lasting $\sim 5 \mathrm{~d}$ and a chronic phase that lingers in survivors of ecdysis. Shrimp with a chronic phase infection present no melanized lesions or abnormal behavior and histologically present normal cuticular epithelium. However, they display marked hypertrophy of the lymphoid organ (LO) with the presence of numerous LO spheroids (LOS) (Hasson et al. 1999b, Srisuvan et al. 2005).

Over 48 wk following TSV infection of juvenile Penaeus vannamei, in situ hybridization (ISH) was able to detect TSV within the LOS up to Week 32, even though LOS remained evident thereafter up to Week 48 post-infection (pi) (Hasson et al. 1999b). RTPCR and real-time quantitative (q)RT-PCR have been developed to detect TSV (Nunan et al. 1998, Tang et al. 2004) and the latter test was able to detect the virus in LO, gill and pleopod tissues in the chronic phase of the disease up to $23 \mathrm{wk}$ pi when the study was terminated (Tang et al. 2004). A monoclonal antibody (1A1) generated to a TSV isolate from Hawaii (circa 1994) used for immunohistochemistry can detect the virus in fixed tissue sections but the reactivity is limited to related isolates (Poulos et al. 1999, Erickson et al. 2002). However, the utility of IHC has not been investigated during chronic phase infection.

Studies to date have shown that accurate diagnosis of TSV is dependent upon the stage of infection and the nature of the isolate. The selection of diagnostic specimens and TSV detection methods becomes more important to diagnose the infection once disease signs abate as infection passes through the transition stage and the virus becomes sequestered in the LO as infection progresses to the chronic stage (Hasson et al. 1999b, Srisuvan et al. 2005). This can be especially important for screening overtly healthy broodstock and postlarvae in areas where TSV is endemic. This study was undertaken to determine which methods most reliably detect TSV in the chronic phase of infection when virus levels decrease.

\section{MATERIALS AND METHODS}

Juvenile specific pathogen-free (SPF) Kona stock Penaeus vannamei $(\mathrm{n}=300)$ obtained from the Oceanic Institute (Hawaii) breeding program, were injected intramuscularly with a shrimp tissue homogenate containing the Hawaii isolate of TSV (TSVUS-HI-94). The shrimp were maintained in a $1000 \mathrm{l}$ tank fitted with a biological filter and aeration, and were fed ad libitum once per day with a pelleted ration ( $35 \%$ Rangen) over the duration of the trial ( $60 \mathrm{wk})$. Two shrimp were sampled at each time point. Hemolymph was withdrawn from the ventral sinus into a syringe containing $10 \%$ sodium citrate to prevent coagulation, pleopods were collected in 95\% ethanol, the cephalothorax was fixed in Davidson's alcohol-formalin-acetic acid (AFA) fixative and the tail muscle was frozen at $-80^{\circ} \mathrm{C}$. Fixed cephalothoraxes were sectioned for histology and stained using Mayer-Bennett hematoxylin-eosin (H\&E) phloxine as described by Bell \& Lightner (1988). In situ hybridization (ISH) and immunohistochemistry (IHC) were performed on consecutive $4 \mu \mathrm{m}$ sections. Digoxigeninlabeled TSV-specific DNA probes Q1 and P15 (a mix of $10 \mathrm{ng} \mathrm{ml}^{-1}$ each) were prepared and used for ISH as described by Hasson et al. (1999c). Anti-TSV monoclonal antibody $1 \mathrm{~A} 1$ was used for IHC as previously described (Poulos et al. 2001), except that the antibody was purified from hybridoma culture fluid using DEAE-cellulose and used at a concentration of $80 \mu \mathrm{g} \mathrm{ml}^{-1}$. Midsagittal sections of the cephalothorax displaying the lymphoid organ (LO) were obtained for histology, ISH and IHC. RNA was isolated from hemolymph and pleopod samples using the RNAEasy Mini kit (QIAGEN) according to the manufacturer's instructions. RT-PCR was performed using the GeneAmp ${ }^{\circledR}$ EZ rTth RNA PCR kit (ABI) and TSV primers 9195/9992 in a $50 \mu \mathrm{l}$ reaction containing $10 \mu \mathrm{l}$ RNA template (Nunan at al. 1998, OIE 2006). qRTPCR was performed using an ABI GeneAmp ${ }^{\circledR} 5700$ sequence detection system, the TaqMan ${ }^{\circledR}$ probe TSV P1, TSV primers $1004 \mathrm{~F} / 1075 \mathrm{R}$ and 1 to $25 \mathrm{ng}$ RNA as described by Tang et al. (2004). All RNA samples were tested in duplicate. A standard curve was determined using dilutions of RNA transcribed from the pTSV-1 plasmid as described by Tang et al. (2004). qRT-PCR data acquisition and analysis utilized the GeneAmp ${ }^{\circledR} 5700$ software.

\section{RESULTS}

Acute phase TSV-induced mortalities commenced on Day 2 pi and continued until Day 8 pi by which time cumulative mortality was $76 \%$. Two shrimp were sampled from the survivors starting at Week 7 pi for a total of 19 time points (38 individual shrimp) over the 60 wk duration of the study. TSV was confirmed in a pool of tissues sampled during the acute phase by RTPCR (Fig. 1A). Histological sections of cephalothorax tissues sampled during the acute phase (Day 5 pi) also demonstrated strong ISH and IHC signals in the peripheral sheath cells of lymphoid organ tubules (Fig. 2A,B). Throughout the chronic phase, histology revealed the presence of LOS in all shrimp analyzed. The presence of TSV in the lymphoid organ was confirmed by ISH and IHC and ISH also detected TSV in ectopic spheroids. Compared to ISH, IHC detected 


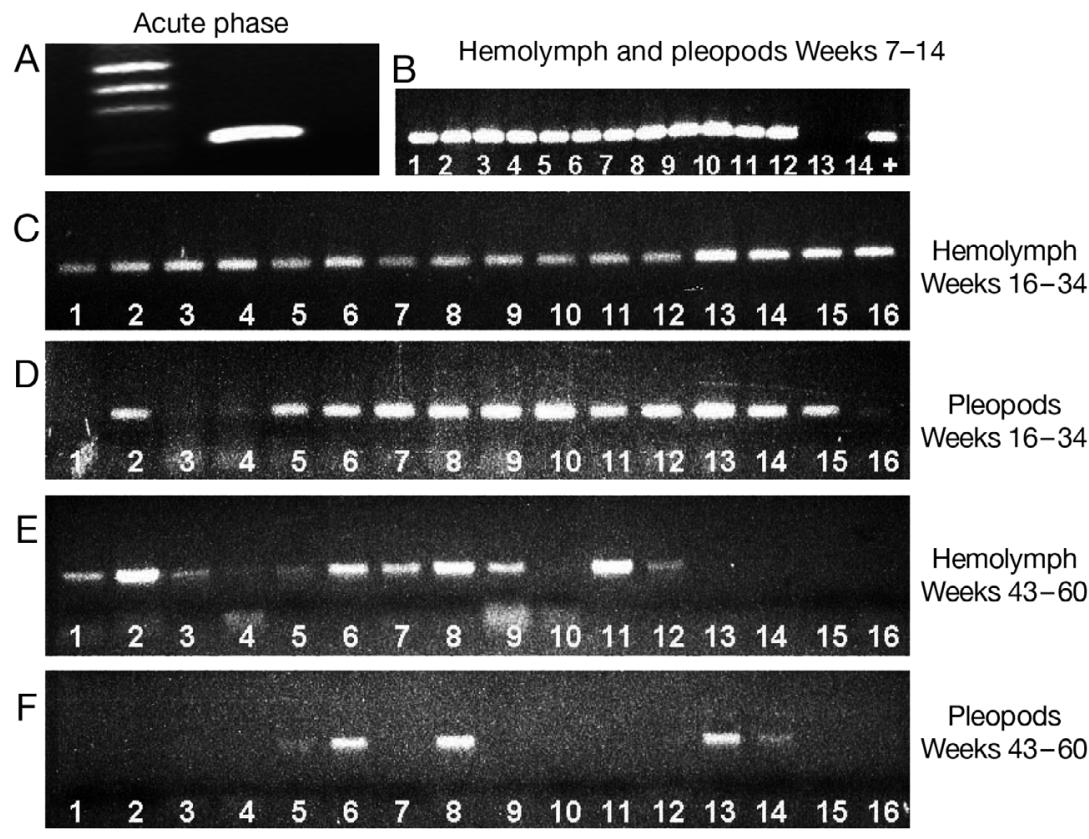

Fig. 1. Penaeus vannamei. Conventional RT-PCR run on RNA extracted from hemolymph and pleopod samples using TSV primers 9195/9992. (A) Molecular weight marker (Lane 1) and acute phase TSV pooled sample (Lane 2) amplicon size = $231 \mathrm{bp}$. (B) Hemolymph samples from Weeks 7 (Lanes 1,2), 11 (Lanes 3,4), and 14 (Lanes 5, 6); pleopods from Weeks 7 (Lanes 7, 8), 11 (Lanes 9,10), and 14 (Lanes 11, 12); uninfected control (Lane 13), no template control (Lane 14) and positive control (+). (C) Hemolymph samples from Weeks 16 (Lanes 1,2), 19 (Lanes 3,4), 21 (Lanes 5,6), 24 (Lanes 7, 8), 26 (Lanes 9,10), 29 (Lanes 11,12), 32 (Lanes 13,14), and 34 (Lanes 15,16). (D) Pleopod samples from Weeks 16 (Lanes 1,2), 19 (Lanes 3,4), 21 (Lanes 5,6), 24 (Lanes 7, 8), 26 (Lanes 9,10), 29 (Lanes 11,12), 32 (Lanes 13,14), and 34 (Lanes 15,16). (E) Hemolymph samples from Weeks 43 (Lanes 1,2), 46 (Lanes 3,4), 50 (Lanes 5,6), 52 (Lanes 7,8), 55 (Lanes 9,10), 57 (Lanes 11,12), and 60 (Lanes 13,14), and uninfected control (Lanes 15,16). (F) Pleopod samples from Weeks 43 (Lanes 1,2), 46 (Lanes 3,4), 48 (Lanes 5,6), 50 (Lanes 7,8), 52 (Lanes 9,10), 55 (Lanes 11,12), 57 (Lanes 13,14), and 60 (Lanes 15,16)

experiment. qRT-PCR revealed that the RNA isolated from hemolymph generally contained 10 to 100 times or more copies of TSV RNA than did pleopods sampled from the same shrimp (Fig. 3). A summary of the RT-PCR and qRT-PCR data is provided in Table 1.

\section{DISCUSSION}

As documented in numerous studies, acute phase TSV infection is easily confirmed by any of several diagnostic methods currently available (Lightner et al. 1995, Hasson et al. 1999b, Erickson et al. 2002, Nunan et al. 2003). Transitional and early chronic phase TSV infection is also reliably diagnosed by histology or molecular methods (Hasson et al. 1999a, Tang et al. 2004). However, detection of reduced virus levels present during late chronic phase infection after gross signs and most histological lesions have been resolved is more problematic. The impact of shrimp with chronic infections needs closer examination now that TSV has spread to most shrimp-farming regions of the world. In areas where TSV is endemic, there is a need to detect virus present at very low levels in shrimp intended for use as

fewer reactive sites at generally lower intensity in the lymphoid organ, and signals diminished as the chronic phase progressed. Negative and weak (Grade 1 to 2; see Lightner 1996 for grading scale) ISH and IHC reactions were first noted from Week 24 pi onward (Fig. 2C-F).

Using RNA isolated from hemolymph and pleopods, TSV was detected by RT-PCR early in the chronic phase ( 7 to 14 wk pi), but detection became more variable using pleopods sampled at later times (Fig. 1B,D,F). In contrast, TSV RNA was consistently detected in hemolymph sampled up to Week 60 pi, when TSV was not detected in the final 2 samples (Fig. 1B,C,E). Using pleopod RNA, 11 of 16 samples collected between weeks 43 and 60 were RT-PCR negative (Fig. 1F), whereas only 2 of 14 hemolymph RNA samples were negative (Fig. 1E). In contrast, qRT-PCR detected TSV in all but 1 sample (a Week 19 pleopod) collected over the $60 \mathrm{wk}$ duration of the broodstock due to the risks of vertical transmission of TSV to seed stocks and virus translocation to other farms or regions, and the decreased value of shrimp that are not certifiable as SPF for TSV. To address this, we undertook this study to investigate which diagnostic methods can reliably detect TSV in shrimp that survived acute infection to develop chronic phase infections.

Pleopods and hemolymph used here are preferred samples to use for the PCR-based detection of nonenteric shrimp pathogens because they can be obtained without sacrificing the shrimp. Amongst cephalothoraxes analyzed by H\&E histology, ISH and IHC, only ISH was able to confirm the presence of TSV throughout the trial. Although histology using H\&E staining also detected LOS throughout the trial, determining the cause requires additional testing. Using IHC (Poulos et al. 1999), reactions progressively diminished with time over the course of the 

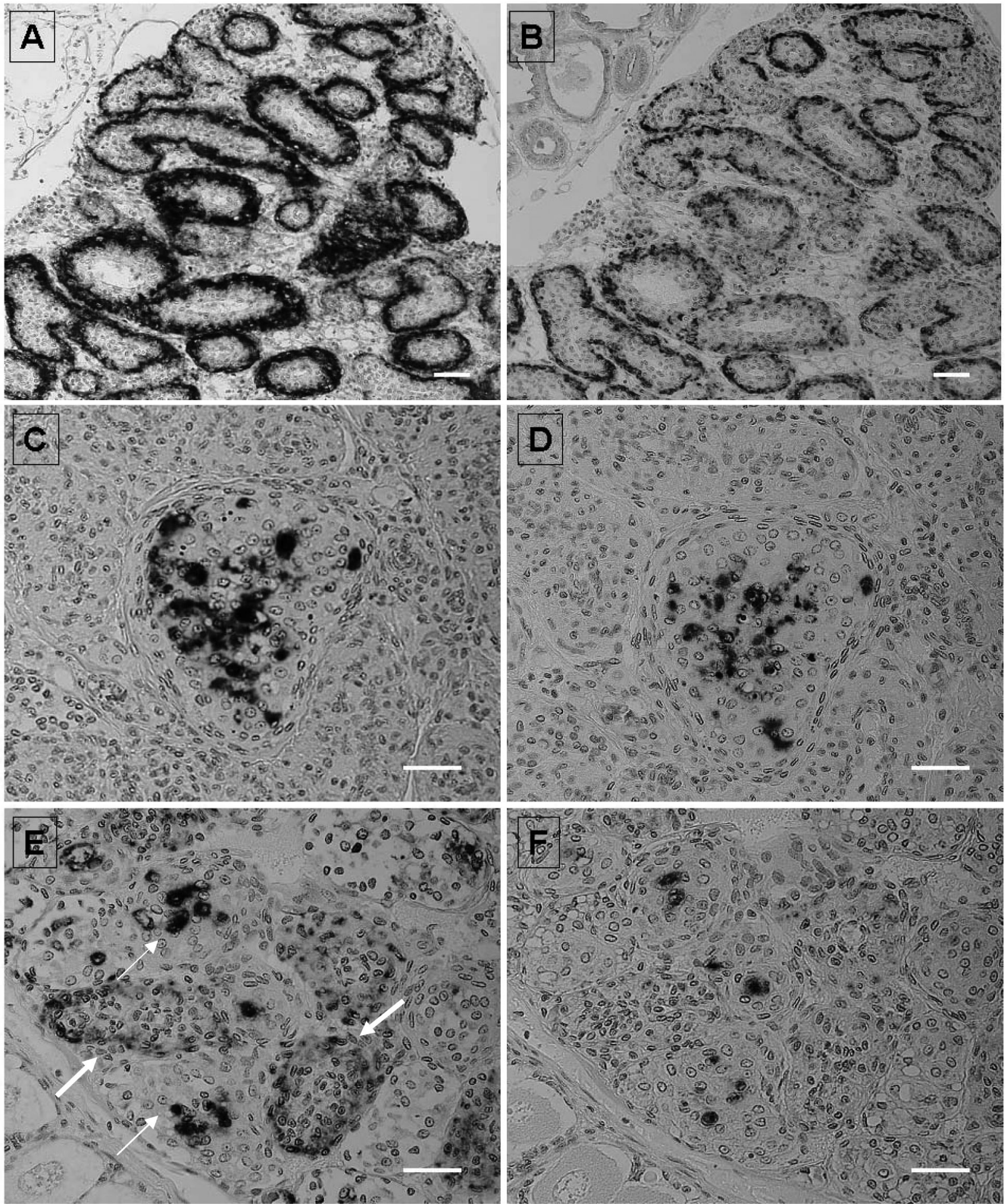

Fig. 2. Penaeus vannamei. In situ hybridization (ISH) and immunohistochemistry (IHC) on consecutive sections of lymphoid organs from shrimp infected with TSV. (A) ISH 5 d post-infection (pi). (B) IHC 5 d pi. (C) ISH 43 wk pi. (D) IHC 43 wk pi. (E) ISH $50 \mathrm{wk}$ pi. (F) IHC 50 wk pi. (A,B) Intense TSV blue-black positive reaction is shown in peripheral parenchymal cells of lymphoid organ tubules, which is characteristic of the transition phase of infection, when circulating virus in the hemolymph is filtered from the hemolymph and accumulated; (C-F) show TSV-positive cells in lymphoid organ spheroids (LOS) typical of the chronic phase of infection and which are the only location in the shrimp where TSV replication can be demonstrated; of interest in (E) are both TSV replicative cells (thin arrows) and filtered TSV in otherwise normal appearing peripheral LO parenchymal cells (thick arrows). Scale bars $=25 \mu \mathrm{m}$ 
Table 1. Penaeus vannamei. Summary of histology, in situ hybridization (ISH), immunohistochemistry (IHC), conventional RT-PCR and qRT-PCR results in shrimp during the chronic phase of TSV infection (pi: post-infection). LO(S): lymphoid organ (spheroids). G0-G4: grading scale from Hasson et al. (1999a). nd: not detected

\begin{tabular}{|c|c|c|c|c|c|c|c|}
\hline \multirow[t]{2}{*}{ Week pi } & \multicolumn{3}{|c|}{ Davidson's fixed tissues } & \multicolumn{2}{|c|}{ Conventional RT-PCR } & \multicolumn{2}{|c|}{ qRT-PCR (copies ng ${ }^{-1}$ RNA) } \\
\hline & LOS & ISH & IHC & Hemolymph & Pleopods & Hemolymph & Pleopods \\
\hline 7 & G3 & G3 & $\mathrm{G} 2-3$ & Positive & Positive & $5.48 \times 10^{5}$ & $1.80 \times 10^{5}$ \\
\hline 7 & G3 & G3 & G2 & Positive & Positive & $1.88 \times 10^{6}$ & $1.04 \times 10^{5}$ \\
\hline 11 & G4 & G3 & G2 & Positive & Positive & $3.64 \times 10^{6}$ & $2.88 \times 10^{5}$ \\
\hline 11 & G4 & G3 & G1 & Positive & Positive & $1.67 \times 10^{7}$ & $4.56 \times 10^{5}$ \\
\hline 14 & G3-4 & G3 & G2 & Positive & Positive & $7.75 \times 10^{7}$ & $8.80 \times 10^{4}$ \\
\hline 14 & G3-4 & G4 & $\mathrm{G} 2-3$ & Positive & Positive & $4.96 \times 10^{7}$ & $1.01 \times 10^{6}$ \\
\hline 16 & G3-4 & G3 & G2 & Positive & nd & $2.23 \times 10^{7}$ & $1.67 \times 10^{3}$ \\
\hline 16 & G3-4 & G4 & G2-3 & Positive & Positive & $6.15 \times 10^{5}$ & $1.32 \times 10^{4}$ \\
\hline 19 & G3 & G3 & G2 & Positive & Weak positive & $1.96 \times 10^{7}$ & $1.22 \times 10^{2}$ \\
\hline 19 & No LO & G3 & G2 & Positive & Weak positive & $5.60 \times 10^{6}$ & nd \\
\hline 21 & G3-4 & G4 & G2 & Positive & Positive & $5.33 \times 10^{5}$ & $3.43 \times 10^{1}$ \\
\hline 21 & G3-4 & G3 & G2 & Positive & Positive & $2.24 \times 10^{7}$ & $5.69 \times 10^{4}$ \\
\hline 24 & G3 & G3 & G2 & Positive & Positive & $1.08 \times 10^{6}$ & $5.30 \times 10^{4}$ \\
\hline 24 & $\mathrm{G} 2-3$ & G2 & G1-2 & Positive & Positive & $1.21 \times 10^{6}$ & $1.19 \times 10^{4}$ \\
\hline 26 & G3 & G2 & G0 & Positive & Positive & $6.28 \times 10^{7}$ & $1.92 \times 10^{5}$ \\
\hline 26 & G3 & G3-4 & G1 & Positive & Positive & $2.34 \times 10^{7}$ & $8.23 \times 10^{2}$ \\
\hline 29 & G1-2 & G3-4 & G0 & Positive & Positive & $2.18 \times 10^{8}$ & $1.57 \times 10^{5}$ \\
\hline 29 & G3-4 & G2 & G1 & Positive & Positive & $9.70 \times 10^{5}$ & $1.06 \times 10^{4}$ \\
\hline 32 & G3-4 & G2 & G1 & Positive & Positive & $2.90 \times 10^{6}$ & $5.84 \times 10^{4}$ \\
\hline 32 & G3 & G3-4 & G1-2 & Positive & Positive & $9.51 \times 10^{7}$ & $4.64 \times 10^{3}$ \\
\hline 34 & G4 & G2 & G1 & Positive & Positive & $6.08 \times 10^{7}$ & $1.03 \times 10^{5}$ \\
\hline 34 & G3 & G2 & G0 & Positive & Weak positive & $1.27 \times 10^{7}$ & $3.32 \times 10^{4}$ \\
\hline 43 & G1-2 & G2-3 & G2 & Positive & nd & $9.72 \times 10^{2}$ & $8.01 \times 10^{2}$ \\
\hline 43 & $\mathrm{G} 2-3$ & G2 & G1 & Positive & nd & $1.63 \times 10^{5}$ & $1.26 \times 10^{2}$ \\
\hline 46 & G3-4 & $\mathrm{G} 2-3$ & G1-2 & Positive & nd & $1.08 \times 10^{4}$ & $8.92 \times 10^{2}$ \\
\hline 46 & G3-4 & G3 & G0 & Weak positive & nd & $1.55 \times 10^{3}$ & $2.20 \times 10^{2}$ \\
\hline $48^{\mathrm{a}}$ & - & - & - & - & Weak positive & - & $1.66 \times 10^{3}$ \\
\hline 48 & - & - & - & - & Positive & - & $1.59 \times 10^{3}$ \\
\hline 50 & G2 & G3-4 & G2 & Positive & nd & $2.08 \times 10^{4}$ & $1.54 \times 10^{3}$ \\
\hline 50 & G3 & G3 & G2 & Positive & Positive & $3.80 \times 10^{5}$ & $9.52 \times 10^{3}$ \\
\hline 52 & $\mathrm{G} 2$ & G2 & G1 & Positive & nd & $3.36 \times 10^{3}$ & $1.62 \times 10^{2}$ \\
\hline 52 & G2 & G2 & G1 & Positive & nd & $1.52 \times 10^{4}$ & $6.12 \times 10^{3}$ \\
\hline 55 & G3 & G2 & G1-2 & Positive & nd & $5.51 \times 10^{3}$ & $1.02 \times 10^{3}$ \\
\hline 55 & G3 & G2 & G1 & Weak Positive & nd & $5.82 \times 10^{3}$ & $3.10 \times 10^{2}$ \\
\hline 57 & G3 & G2 & G1 & Positive & Positive & $2.43 \times 10^{5}$ & $2.63 \times 10^{4}$ \\
\hline 57 & G3 & G1-2 & G1 & Positive & Weak Positive & $2.32 \times 10^{5}$ & $8.60 \times 10^{4}$ \\
\hline 60 & G2 & G1 & G0 & nd & nd & $1.42 \times 10^{3}$ & $1.76 \times 10^{3}$ \\
\hline 60 & G3 & G0 & G0 & nd & nd & $1.14 \times 10^{3}$ & $4.88 \times 10^{3}$ \\
\hline
\end{tabular}

trial and after Week 24, many samples that were ISH-positive were not detectable using IHC. The better reactivity of ISH compared to IHC might be explained by viral coat protein being translated and fewer particles being assembled during the late stages of the chronic phase, although the viral genome is still replicated at low levels. The amount of primary antibody used in the IHC test may also have been lower than ideal to obtain optimal visual intensity as the intensity was never as high as that obtained by ISH. Protein and RNA-based dot blot titration of the same tissue would need to be done to assess detection sensitivity differences.

Hemolymph provided the best RNA source for TSV and allowed virus to be detected up to $57 \mathrm{wk}$ pi by RTPCR (OIE 2006). Pleopods were almost equally suitable as hemolymph when qRT-PCR was used to detect viral RNA, although RNA copy numbers present in hemolymph were often over 100-fold higher than in pleopods. A possible reason for this was that pleopods were more difficult to process than hemolymph, requiring grinding, and less intact RNA might have resulted. It is also possible that polysaccharides derived from cuticle were co-extracted from pleopod samples and interfered with the RT-PCR. Moreover, sequestering of virus in lymphoid organ spheroids and generalized clearing of infection might result in little or no replication occurring in tissues such as pleopods, whereas virus replicating in LOS may continue to be released into circulating hemolymph. The RT-PCR test employed in this study uses a single-tube, singleenzyme system, which would not be as sensitive as 


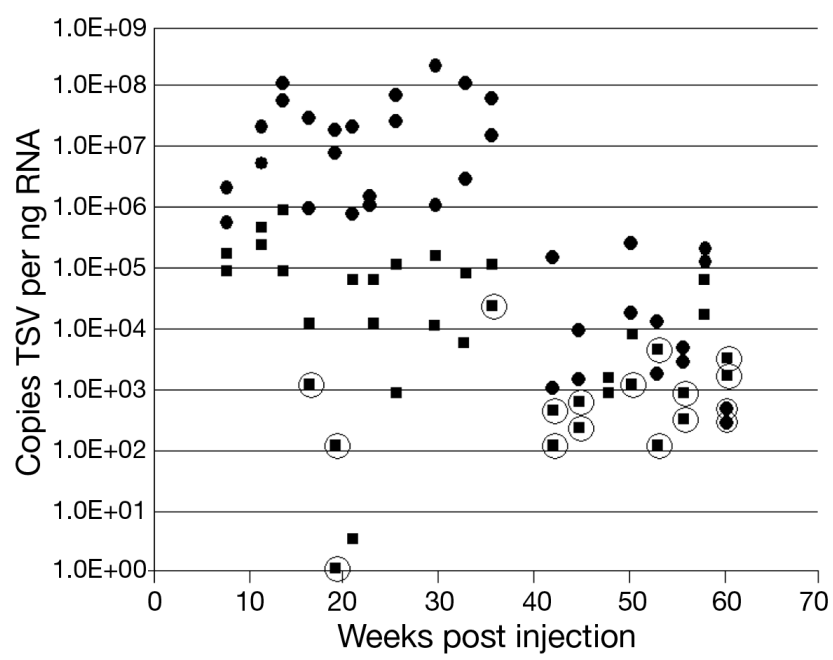

Fig. 3. Penaeus vannamei. TSV copy number per ng RNA from chronic phase shrimp 7-60 wk post-infection. RT-PCR data from Table 1. RNA extracted from hemolymph (•) or pleopods (घ). Circled values indicate samples that were negative by conventional RT-PCR but positive by quantitative RT-PCR

other cDNA amplification methods employing a 2 step PCR. Moreover, direct comparison of the sensitivity of RT-PCR and qRT-PCR tests could not be made due to the use of different template volumes. However, in general, the data showed the RT-PCR test to require in the order of 1000 to 10000 TSV RNA copies for consistent amplification of a DNA product detectable by gel electrophoresis, whereas the qRT-PCR test required as few as 100 TSV RNA copies for clear detection (Tang et al. 2004).

Determining the most appropriate method and sample type to detect TSV is important in shrimp that survive acute infection, particularly in areas where TSV is endemic and where survivors might be used as broodstock. This study shows hemolymph and pleopods provide non-lethal sources of TSV RNA for diagnosis of chronic infection by RT-PCR or qRT-PCR. However, RT-PCR using pleopods as a RNA source or the use of methods such as IHC or histology alone will not reliably detect the chronic phase TSV infection. As qRT-PCR utilizing hemolymph RNA and ISH analysis of tissue sections containing lymphoid organ were clearly the most reliable methods for detecting the virus in shrimp for more than $1 \mathrm{yr}$ after the chronic phase of the disease cycle, these methods are recommended for detecting low-level TSV infection.

Acknowledgements. The United States Marine Shrimp Farming Program, CSREES, USDA and a grant from the National Fisheries Institute supported this work. The authors thank Dr. C. Pantoja for histological analysis of the samples, R. Redman for processing histological samples, and the staff at the UAZ
Aquaculture Pathology West Campus Agricultural Center for the care and feeding of the chronic-phase shrimp over the 13 mo duration of the study.

\section{LITERATURE CITED}

Bell TA, Lightner DV (1988) A handbook of normal penaeid shrimp histology. World Aquaculture Society, Baton Rouge, LA

Brock JA (1997) Special topic review: Taura syndrome, a disease important to shrimp farms in the Americas. World J Microbiol Biotechnol 13:415-418

Brock JA, Gose RB, Lightner DV, Hasson KW (1995) An overview on Taura syndrome, an important disease of farmed Penaeus vannamei. In: Browdy CL, Hopkins JS (eds) Swimming through troubled water. Proceedings of the special session on shrimp farming. Aquaculture '95. World Aquaculture Society, Baton Rouge, LA, p 84-94

Erickson HS, Zarain-Herzberg M, Lightner DV (2002) Detection of Taura syndrome virus (TSV) strain differences using selected diagnostic methods: diagnostic implications in penaeid shrimp. Dis Aquat Org 52:1-10

Erickson HS, Poulos BT, Tang KFJ, Bradley-Dunlop D, Lightner DV (2005) Taura syndrome from Belize represents a unique variant. Dis Aquat Org 64:91-98

- Hasson KW, Lightner DV, Poulos BT, Redman RM, White BL, Brock JA, Bonami JR (1995) Taura syndrome in Penaeus vannamei: demonstration of a viral etiology. Dis Aquat Org 23:115-126

> Hasson KW, Lightner DV, Mohney LM, Redman RM, Poulos BT, White BM (1999a) Taura syndrome virus (TSV) lesion development and the disease cycle in the Pacific white shrimp Penaeus vannamei. Dis Aquat Org 36: 81-93

Hasson KW, Lightner DV, Mohney LM, Redman RM, White BM (1999b) Role of lymphoid organ spheroids in chronic Taura syndrome virus (TSV) infections in Penaeus vannamei. Dis Aquat Org 38:93-105

$>$ Hasson KW, Lightner DV, Mari J, Bonami JR and others (1999c) The geographic distribution of Taura syndrome virus (TSV) in the Americas: determination by histopathology and in situ hybridization using TSV-specific cDNA probes. Aquaculture 171:13-26

Jimenez R (1992) Sindrome de Taura (Resumen). Acuacultura Ecuador 1:1-16

Lien TW, Hsiung HC, Huang CC, Song YL (2002) Genomic similarity of Taura syndrome virus (TSV) between Taiwan and western hemisphere isolates. Fish Pathol 37:71-75

Lightner DV (ed) (1996) A handbook of shrimp pathology and diagnostic procedures for diseases of cultured penaeid shrimp. World Aquaculture Society, Baton Rouge, LA

Lightner DV, Redman RM, Hasson KW, Pantoja CR (1995) Taura syndrome in Penaeus vannamei (Crustacea: Decapoda): gross signs, histopathology and ultrastructure. Dis Aquat Org 21:53-59

Nielsen L, Sang-oum W, Cheevadhanarak S, Flegel TW (2005) Taura syndrome virus (TSV) in Thailand and its relationship to TSV in China and the Americas. Dis Aquat Org 63:101-106

Nunan LM, Poulos BT, Lightner DV (1998) Reverse transcription polymerase chain reaction (RT-PCR) used for the detection of Taura Syndrome Virus (TSV) in experimentally infected shrimp. Dis Aquat Org 34:87-91

Nunan LM, Tang-Nelson K, Lightner DV (2004) Real-time RT-PCR determination of viral copy number in Penaeus 
vannamei experimentally infected with Taura syndrome virus. Aquaculture 229:1-10

OIE (Office International des Epizooties - World Animal Health Organization) (2006) Manual of diagnostic tests for aquatic animals, 5th edn. OIE, Paris

Poulos BT, Kibler R, Bradley-Dunlop D, Mohney LL, Lightner DV (1999) Production and use of antibodies for the detection of Taura syndrome virus in penaeid shrimp. Dis Aquat Org 37:99-106

Poulos BT, Pantoja CR, Bradley-Dunlop D, Aguilar J, Lightner DV (2001) Development and application of monoclonal antibodies for the detection of white spot syndrome virus of penaeid shrimp. Dis Aquat Org 47:13-23

Robles-Sikisaka R, Hasson KW, Garcia DK, Brovont KE, Cleveland KD, Klimpel KR, Dhar AK (2002) Genetic variation and immunohistochemical differences among geographic isolates of Taura syndrome virus of penaeid shrimp. J Gen Virol 83:3123-3130

Editorial responsibility: Ken Hasson, College Station, Texas, USA
Rosenberry B (2002) World shrimp farming 2002, No. 15. Shrimp News International, San Diego, CA

Srisuvan T, Tang KFJ, Lightner DV (2005) Experimental infection of Penaeus monodon with Taura syndrome virus (TSV). Dis Aquat Org 67:1-8

Tang KF, Lightner DV (2005) Phylogenetic analysis of Taura syndrome virus isolates collected between 1993 and 2004 and virulence comparison between two isolates representing different genetic variants. Virus Res 112:69-76

Tang KFJ, Wang J, Lightner DV (2004) Quantitation of Taura syndrome virus by real-time RT-PCR with a TaqMan assay. J Virol Methods 115:109-114

> Tu C, Huang HT, Chuang SH, Hsu JP and others (1999) Taura syndrome in Pacific white shrimp Penaeus vannamei cultured in Taiwan. Dis Aquat Org 38:159-161

Yu CI, Song YL (2000) Outbreaks of Taura syndrome in pacific white shrimp Penaeus vannamei cultured in Taiwan. Fish Pathol 35:21-24

Submitted: May 9, 2008; Accepted: October 8, 2008 Proofs received from author(s): December 17, 2008 